\title{
Multi-state succession in wetlands: a novel use of state and transition models
}

\author{
C. L. Zweig ${ }^{1}$ And W. M. Kitchens \\ Florida Cooperative Fish and Wildlife Research Unit, Box 110485, Building 810, University of Florida, \\ Gainesville, Florida 32611-0485 USA
}

\begin{abstract}
The complexity of ecosystems and mechanisms of succession are often simplified by linear and mathematical models used to understand and predict system behavior. Such models often do not incorporate multivariate, nonlinear feedbacks in pattern and process that include multiple scales of organization inherent within real-world systems. Wetlands are ecosystems with unique, nonlinear patterns of succession due to the regular, but often inconstant, presence of water on the landscape. We develop a general, nonspatial state and transition ( $\mathrm{S}$ and $\mathrm{T}$ ) succession conceptual model for wetlands and apply the general framework by creating annotated succession/management models and hypotheses for use in impact analysis on a portion of an imperiled wetland. The $\mathrm{S}$ and $\mathrm{T}$ models for our study area, Water Conservation Area 3A South (WCA3), Florida, USA, included hydrologic and peat depth values from multivariate analyses and classification and regression trees. We used the freeware Vegetation Dynamics Development Tool as an exploratory application to evaluate our $\mathrm{S}$ and $\mathrm{T}$ models with different management actions (equal chance [a control condition], deeper conditions, dry conditions, and increased hydrologic range) for three communities: slough, sawgrass (Cladium jamaicense), and wet prairie. Deeper conditions and increased hydrologic range behaved similarly, with the transition of community states to deeper states, particularly for sawgrass and slough. Hydrology is the primary mechanism for multi-state transitions within our study period, and we show both an immediate and lagged effect on vegetation, depending on community state. We consider these $\mathrm{S}$ and $\mathrm{T}$ succession models as a fraction of the framework for the Everglades. They are hypotheses for use in adaptive management, represent the community response to hydrology, and illustrate which aspects of hydrologic variability are important to community structure. We intend for these models to act as a foundation for further restoration management and experimentation which will refine transition and threshold concepts.
\end{abstract}

Key words: alternate stable states; CART; Florida Everglades, USA; state and transition models; succession; VDDT; wetlands.

\section{INTRODUCTION}

It is well known that the concept and application of succession theory is extremely complex (Platt and Connell 2003). Yet the complexity of ecosystems and mechanisms of succession are often simplified into linear mathematical models (Ryan et al. 2007) used to understand and predict system behavior. These linear models can not incorporate multivariate, nonlinear feedbacks in pattern and process that include multiple scales of organization inherent within real-world systems (Proulx 2007). It is this complexity that creates the possibility of restoration actions producing unexpected results due to reliance on traditional succession patterns that are no longer valid in a degraded system (Suding et al. 2004). As wetlands are a major ecosystem type currently impacted and being restored by humans, our

Manuscript received 24 July 2008; revised 6 October 2008; accepted 13 October 2008. Corresponding Editor: A. M. Ellison.

${ }^{1}$ E-mail: czweig@ufl.edu goal is to provide a nonlinear, easily interpretable, community-based wetland vegetation change/succession model for use in restoration monitoring and management.

Wetlands have a unique pattern of succession (any vegetation change over time; Peet 1992) due to the regular, but often inconstant, presence of water on the landscape. Accordingly, wetland succession has multiple trajectories and endpoints, created by hydrology, competition, edaphic factors, and other external and internal controls. Typical succession is initiated by a disturbance, partial or total (Platt and Connell 2003), in which the communities are "reset." Succession progresses in a relatively directional manner (Tilman 1990, Sousa and Connell 1992) to one of many endpoints (Law and Morton 1996). Wetland reset points have two possible trajectories that are opposite each other: more aquatic or more terrestrial communities. The position of the wetland's reset point, in the middle of a bidirectional succession, is unique and is a key factor in the diversity of wetlands such as the Pantanal (Alho 2005, Junk et al. 
2006) and the Okavango Delta (Ellery et al. 2003). The initial direction of succession, and whether the ecosystem response is continuous or discontinuous, depends on the intensity of the disturbance that resets succession, current conditions, and vegetative and hydrologic legacies of the site. The intensity of reset determines which species are present to recolonize the affected area.

The variable position of the reset point and its multiple trajectories create the possibility of multiple stable states (Beisner et al. 2003) within dynamic regimes (Mayer and Rietkerk 2004) in vegetation community succession. Transitions between stable states are typically characterized by dramatic changes, e.g., from oligotrophic to eutrophic lakes (Scheffer and Carpenter 2003), but fine-scale changes within communities are also functionally important (Arscott et al. 2002), especially in areas with subtle environmental gradients (Givnish et al. 2008). Here our model accounts for nonlinear succession at multiple scales, including finescale changes from transitions within communities, defined here as state shifts, and changes between communities defined as community shifts.

State and transition ( $\mathrm{S}$ and $\mathrm{T}$ ) models were developed as conceptual models to address the need for flexibility (e.g., open-ended, multidirectional, and adaptive) and nonlinearity in succession models for management (Westoby et al. 1989). They have been widely applied in rangeland, arid, and semiarid grasslands (Allen-Diaz and Bartolome 1998, Bestelmeyer et al. 2006, Quétier et al. 2007), but have had limited use in other ecosystems. They provide a simple, flexible framework for both scientists and managers and apply dynamic vegetation change theory to management models. S and T models may capture the complexity of wetland succession that is unattainable with other models and these approaches offer an excellent opportunity to build an adaptive framework for restoration/management use. This adaptability is especially useful in a time of accelerated human impacts, global climate change, and sea level rise.

An excellent system to test the $\mathrm{S}$ and T model's ability to capture complex, nonlinear interactions for management use is one of the largest restoration projects in the world, the Florida Everglades. The Everglades is a seasonally flooded wetland in subtropical south Florida, USA, which is subject to extremely subtle environmental gradients (north-south elevation gradient of $3 \mathrm{~cm} / \mathrm{km}$ and $1.15 \mathrm{~cm} /$ second flow rate; Kushlan 1990, Riscassi and Schaffranek 2003). Spatial and temporal variance in natural and altered hydrologic regimes maintain a highly heterogeneous landscape. Vegetation dynamics of the system have been modified along with its hydrology and represent a disturbed regime whose successional pathways are unknown. We develop a general, nonspatial, $\mathrm{S}$ and $\mathrm{T}$ succession conceptual model for wetlands, and apply the general framework by creating annotated succession/management models as hypotheses for use in impact analysis on a portion of an imperiled wetland.

\section{Methods}

Study area

Our study area is Water Conservation 3A South (WCA3), one of the largest intact areas of the Everglades ridge and slough landscape in southern Florida (Fig. 1). It comprises approximately 200000 ha and the vegetation communities are subject to several key environmental gradients: an east-west peat depth gradient, north-south elevation gradient, and an artificial north-south water depth gradient due to impoundment. Hydrologic regimes in WCA3 were altered for restoration purposes beginning in 2002, an action that increased hydroperiods and water depths. Climate cycles and water control have resulted in higher maximum water depths and an increased hydrologic range from wet to dry seasons (C. Zweig, unpublished data). This disturbance adds to stress from decades of sustained ponding. We are monitoring WCA3 to track changes in vegetation communities during this altered regime.

\section{General framework}

Our general wetlands $\mathrm{S}$ and $\mathrm{T}$ succession framework loosely follows definitions in Stringham et al. (2003). We constructed our framework with multiple community states within a community and, at this four-year timescale, the transitions between states tend to be dominated by hydrology (Fig. 2). Each community has a finite number of states possible, but the number varies between communities. Transitions between states are considered reversible and have moving thresholds which are less distinct than the thresholds between communities that may require more extreme disturbances to transition. State forcing functions influence state shifts and outside forcing functions influence community shifts. State and outside forcing functions share most factors: hydrologic timing, edaphic factors, autogenic effects, topography, intensity of reset, disturbance, intensity of disturbance, exotic invasion, flow, hydroperiod, nutrient cycles, seed bank, and vegetative and hydrologic legacy. Forcing functions that are considered state-only include competition and microtopography. This framework can accommodate multiple communities and states as the landscape responds to autogenic or allogenic change. We applied this general framework to our study area (Fig. 3), restricted to a temporal scale of $<50$ years. In our systems, the main forcing functions consist of disturbance and long-term hydrologic variation.

\section{Everglades model}

Delineating communities.-Community state analyses were initially conducted for a previous study (Zweig and Kitchens 2008) and are provided here in less detail, as they are input for the $\mathrm{S}$ and $\mathrm{T}$ models. Data for the Everglades analysis are taken from a vegetation monitoring project in WCA3 from 2002 to 2005. Five a priori physiognomic types were identified: slough, 


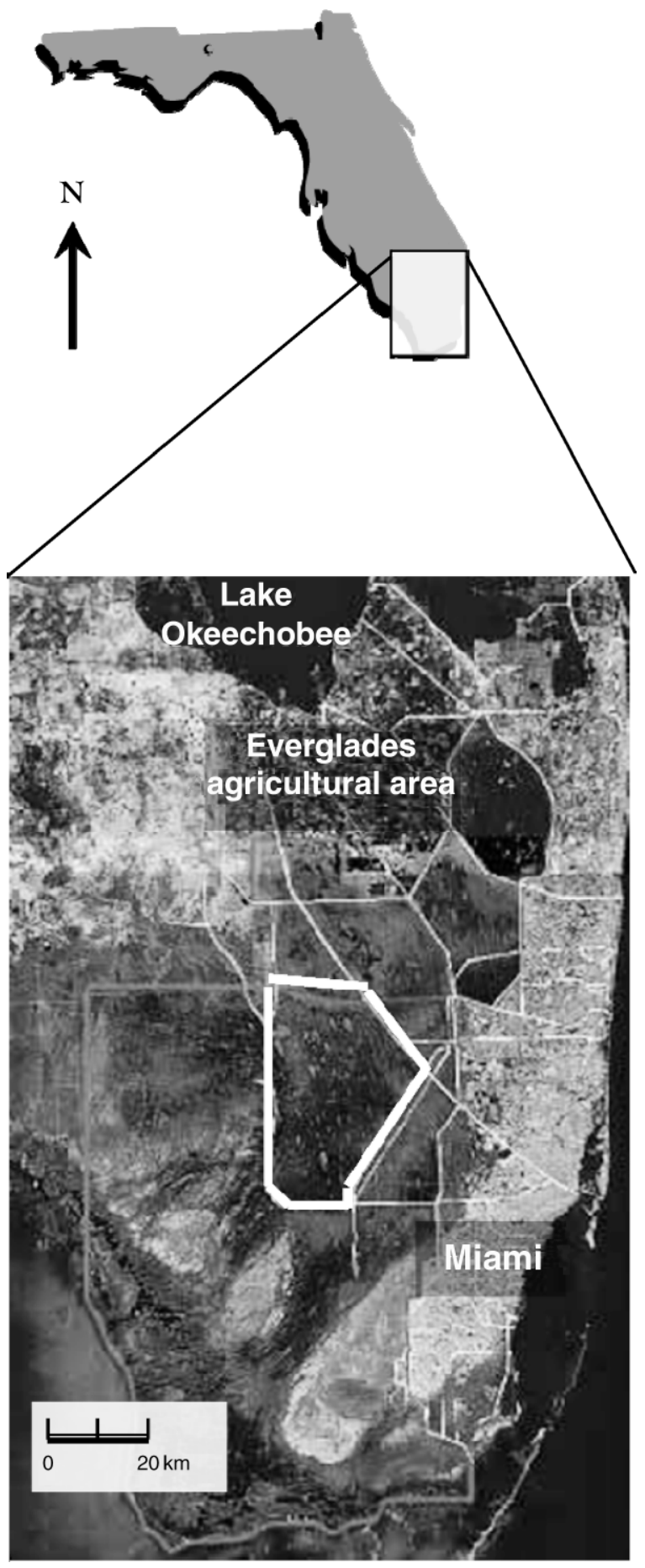

FIG. 1. Satellite view of the Everglades in southern Florida, USA. Our study site, Water Conservation Area 3A South, is outlined in white.

sawgrass, tree/shrub island, cattail, and wet prairie. Two to three transects were placed in each of 20 study plots perpendicular to ecotones, beginning in one a priori type and terminating in another (e.g., slough to sawgrass). We collected $0.25-\mathrm{m}^{2}$ quadrat samples of all above- ground standing biomass at 3-m intervals along a belt transect and included any submerged aquatic plants within the sample. Samples were collected on every transect in each plot at the end of the dry (May-June) and wet season (November-December) of each year. These were sorted by species, counted, dried to a constant mass, and weighed to the nearest $0.1 \mathrm{~g}$. Approximately 9500 samples were collected and processed between 2002 and 2005. Seventeen water wells were installed in December 2002 and historic hydrologic data, from 1991 to 2002, were hindcast using an artificial neural network model (Conrads et al. 2006).

To account for high densities of low-biomass species and high biomass of low-density species, the data were relativized in an index called importance value (IV), calculated by

$$
\text { IV for species } i=\left[\left(R_{\mathrm{d} i}+R_{\mathrm{b} i}\right) / 2\right] \times 100
$$

where $R_{\mathrm{d} i}$ is the relative density of species $i$ and $R_{\mathrm{b} i}$ is the relative biomass of species $i$. Relative measures are the sum of biomass or density of species $i$ divided by the sum of biomass or density of all species within the $1-\mathrm{km}^{2}$ plot. The importance values for all species in a plot sum to 100 . Species that were in less than $5 \%$ of the community samples were considered rare and not included in the analysis.

The IV data for each plot were analyzed using PCORD (McCune and Mefford 1999), a multivariate statistics software, as we were interested in changes of community structure and not focused on one species at a time. For this analysis, we pooled all data within a 1$\mathrm{km}^{2}$ plot for each a priori physiognomic type for each year and referred to them as community samples $(n=$ 234 samples).

We performed a hierarchical, agglomerative cluster analysis on the community samples from every plot and year for three of the a priori vegetation types (wet prairie, $n=47$ samples; slough, $n=72$; and sawgrass, $n=$ 80) using a relative Sorenson distance measure with a flexible beta of -0.25 in order to delineate community states present in our study area. We chose the optimal number of clusters/states with an indicator species analysis (ISA) and identified the associate species for each cluster (Dufrêne and Legendre 1997). Community states were named according to the indicator species from the ISA. We performed a nonmetric multidimensional scaling (Kruskal 1964, Mather 1976) ordination (NMS) on the vegetation community data with Sorensen distance measure, 40 runs with real data, and 50 Monte Carlo. We then constructed a secondary matrix of environmental factors to determine which factors correlate to community state composition in WCA3. PC-ORD overlaid the secondary matrix and calculated correlation coefficients for each environmental variable, which included peat depth and a suite of both recent and historic hydrologic variables (maximum, minimum, and mean of every dry and wet season up to five years 


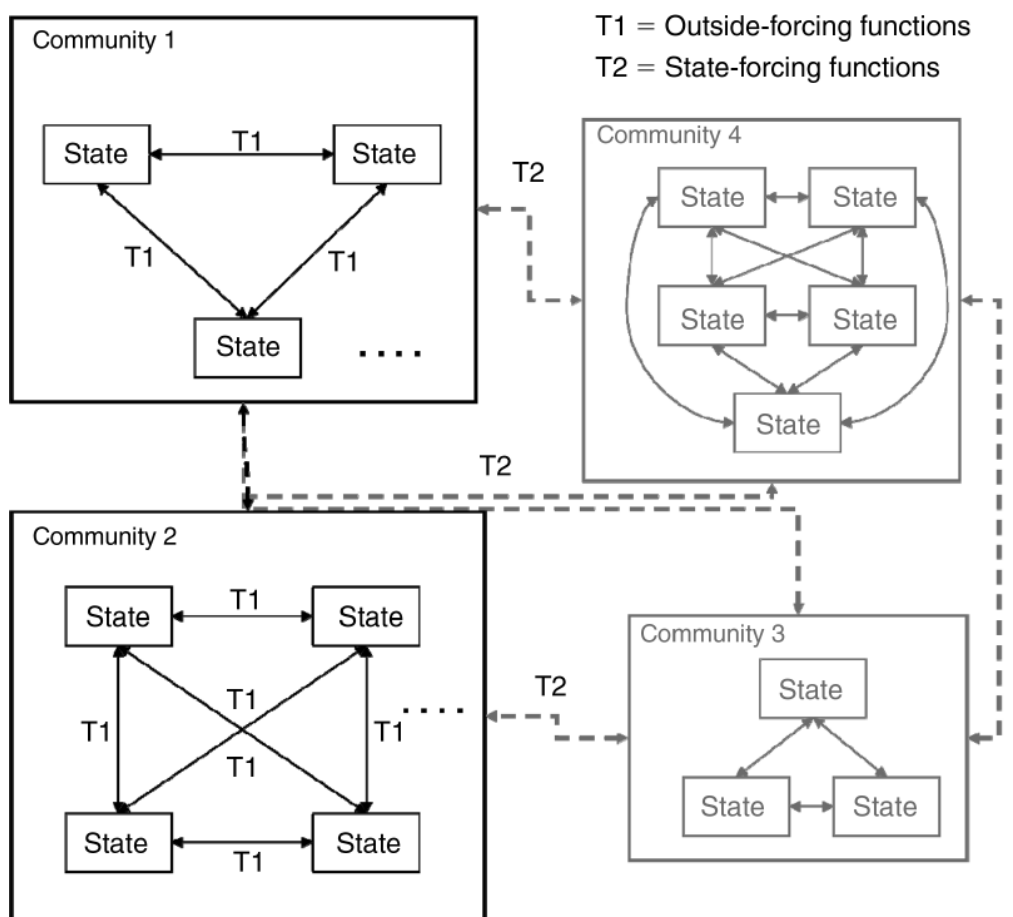

FIg. 2. General state and transition model for wetlands. Transitions between states are considered reversible. State- and outside-forcing functions share most factors: hydrologic timing, edaphic factors, autogenic effects, topography, intensity of reset, disturbance, intensity of disturbance, exotic invasion, flow, hydroperiod, nutrient cycles, seed bank, and vegetative and hydrologic legacy. Forcing functions that are considered state-only include competition and microtopography.

previous to the sample). "Recent," for this analysis, is defined as hydrology affecting the area in the past year and "historic" is hydrology two or more years prior to the sample event.
Classification and regression tree (CART).-We performed a CART analysis (Breiman et al. 1984) on the three physiognomic types of interest (slough, sawgrass, and wet prairie) to provide quantitative

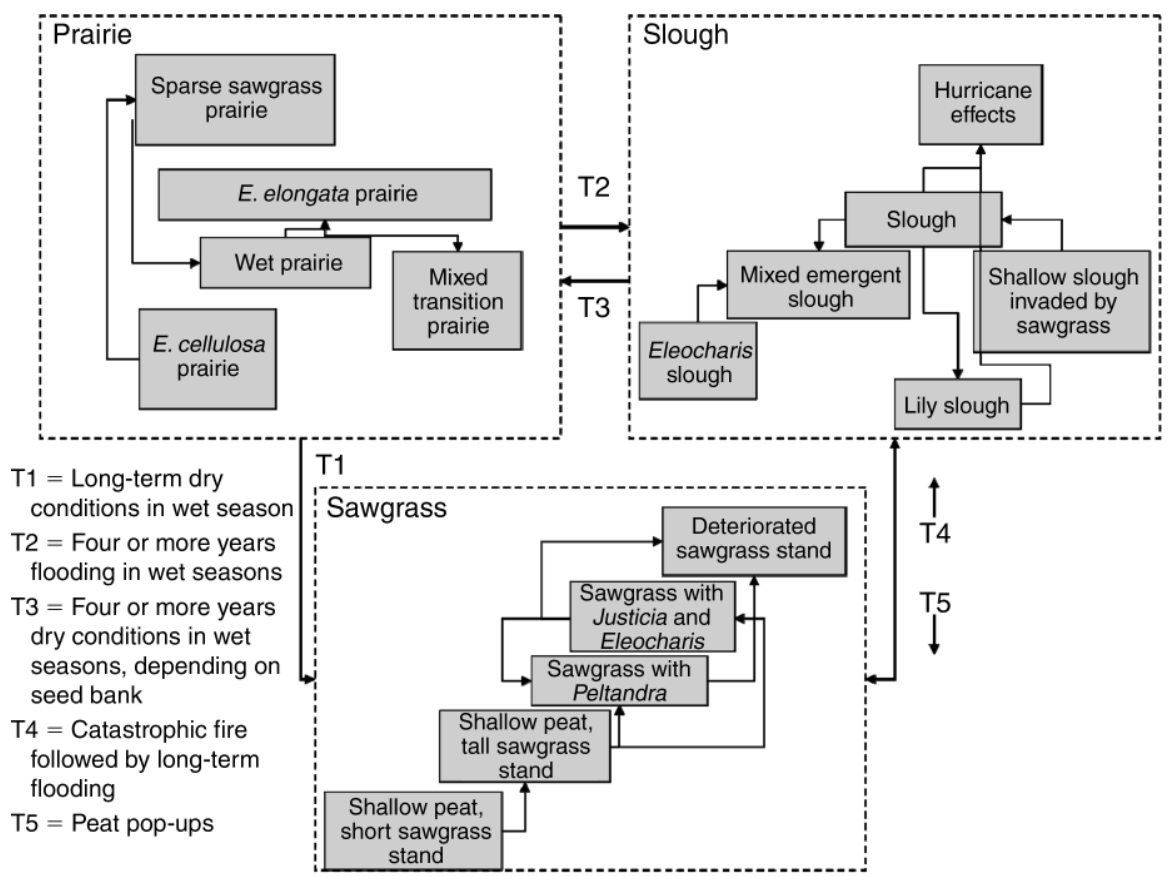

FIG. 3. Landscape-scale state and transition model for Water Conservation Area 3A South in the Everglades, Florida, USA. 
TABLE 1. Importance value (\%; average of relative biomass and relative density) of species within community states in Water Conservation Area 3A South, Everglades, southern Florida, USA.

\begin{tabular}{|c|c|c|c|c|c|c|}
\hline Community and state & $\mathrm{BAC}(\%)$ & CLA $(\%)$ & ELG $(\%)$ & Elsp $(\%)$ & NYO (\%) & Utsp (\%) \\
\hline \multicolumn{7}{|l|}{ Slough } \\
\hline Slough & 2.6 & 1.6 & 49.2 & 3.0 & 15.5 & 28.0 \\
\hline Hurricane effects & 1.5 & 7.7 & 46.2 & 5.0 & 34.3 & 5.2 \\
\hline Shallow slough invaded by sawgrass & 3.9 & 27.1 & 63.4 & 1.1 & 3.4 & 1.1 \\
\hline Mixed emergent slough & 9.8 & 3.6 & 5.8 & 29.7 & 22.5 & 28.5 \\
\hline Lily slough & 0.2 & 4.2 & 15.0 & 5.7 & 48.7 & 26.2 \\
\hline Eleocharis slough & 6.3 & 2.7 & 23.3 & 46.3 & 0.0 & 21.5 \\
\hline \multicolumn{7}{|l|}{ Prairie } \\
\hline E. elongata prairie & 8.6 & 2.1 & 64.4 & 5.0 & 7.0 & 12.9 \\
\hline Wet prairie & 5.3 & 1.8 & 19.7 & 44.0 & 5.2 & 24.0 \\
\hline Sparse sawgrass prairie & 11.7 & 18.3 & 2.8 & 55.7 & 4.8 & 6.7 \\
\hline E. cellulosa prairie & 1.5 & 16.4 & 1.6 & 75.6 & 1.0 & 3.7 \\
\hline Mixed transition prairie & 33.9 & 0.9 & 3.3 & 23.6 & 18.5 & 19.7 \\
\hline \multicolumn{7}{|l|}{ Sawgrass } \\
\hline Sawgrass with Justicia and Eleocharis & 9.4 & 73.7 & 13.6 & 1.0 & 0 & 2.4 \\
\hline Sawgrass with Peltandra & 6.6 & 53.7 & 35.0 & 3.0 & 0 & 1.6 \\
\hline Deteriorated sawgrass strand & 19.6 & 38.0 & 31.6 & 3.9 & 0 & 6.9 \\
\hline Shallow peat, tall sawgrass strand & 10.8 & 59.7 & 0.6 & 26.4 & 0 & 2.5 \\
\hline Shallow peat, short sawgrass strand & 0.0 & 43.0 & 0.0 & 56.5 & 0 & 0.4 \\
\hline
\end{tabular}

Note: Species abbreviations: BAC, Bacopa caroliniana; CLA, Cladium jamaicense; ELG, Eleocharis elongata; Elsp, Eleocharis cellulosa; NYO, Nymphaea odorata; UTsp, Utricularia sp.

measures of environmental variables to annotate the transitions in the $\mathrm{S}$ and $\mathrm{T}$ models, but the sample size of wet prairie was too small to provide results with acceptable error. The CART (S-Plus; StatSci/Mathsoft 1993) analyses classified our community states for slough and sawgrass communities by the environmental variables used in the NMS and provided environmental thresholds that delineated community states. The CART results were interpreted with the NMS results to supply annotated (quantitative) transitions in the $\mathrm{S}$ and $\mathrm{T}$ models, which are normally conceptual, qualitative models.

Vegetation dynamics development tool (VDDT) analysis.-VDDT (Beukema et al. 2003) is a freeware program that simulates succession and disturbance, using $\mathrm{S}$ and $\mathrm{T}$ models, based on two types of userdefined transitions: probabilistic and deterministic. Probabilistic transitions are controlled by management actions or disturbance; and deterministic transitions are based on succession due to time with no disturbance or change in management. There were no probabilistic transitions defined for our simulations, as we considered the changes occurring were due to hydrologic manipulation and not succession due to time. We identified qualitative management actions/disturbances (high and low dry-season water depths, high and low wet-season water depths, high winds, and fire) and associated them with transition probabilities calculated from observed transitions within our $\mathrm{S}$ and $\mathrm{T}$ models, i.e., a high-water wet season will have a $4 \%$ chance to change from a mixed transition prairie state to an Eleocharis elongata Chapman prairie state. We simulated 100-year time intervals with 50 Monte Carlo runs over 500 cells, with vegetation community configuration for 2002 as the initial conditions, for four management actions: equal, wet conditions, dry conditions, and increased hydrologic range. The equal category was added as a control to predict vegetation communities if the probability of all disturbances or management actions were equal and they occurred randomly. Wet conditions had high probability of high water depths in the wet and dry season and VDDT used the associated transition probabilities for each community state with low probabilities of all other disturbances. Dry conditions had high probabilities for low water in the wet and dry season and VDDT used associated community state transition probabilities that included low water in these seasons with low for probabilities of all other disturbances. Increased hydrologic range included high wet seasons and low dry seasons and the particular transition probabilities for community states defined by our $\mathrm{S}$ and $\mathrm{T}$ models.

\section{RESUlts}

\section{Delineating communities and transition probability}

State transitions in the $\mathrm{S}$ and $\mathrm{T}$ model for each a priori group were based on our data, but transitions between communities represent extreme changes that were not present during our study period and are hypotheses only (Fig. 3). The cluster/ISA suggested five prairie states, five sawgrass states, and six slough states from 2002 to 2005 (see Zweig and Kitchens 2008) (Table 1). General transitions (Fig. 4) were supplied by the environmental correlates within the NMS analysis (see Zweig and Kitchens 2008). Transitions were caused by hydrologic alteration that occurred within four years of the sample (Armentano et al. 2006, Zweig and Kitchens 2008). Community composition of prairie states were controlled by water depths in the wet season, but sawgrass 
A) Wet prairie

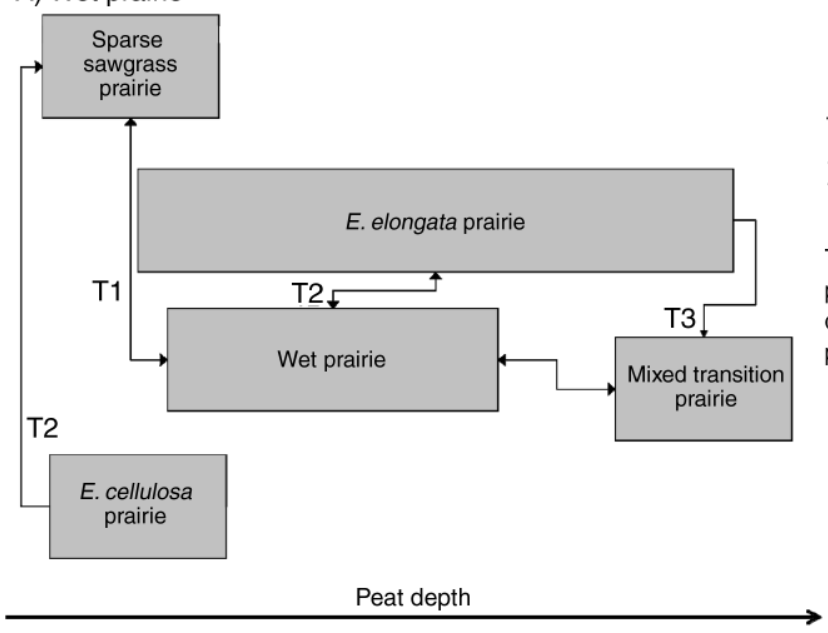

B) Sawgrass

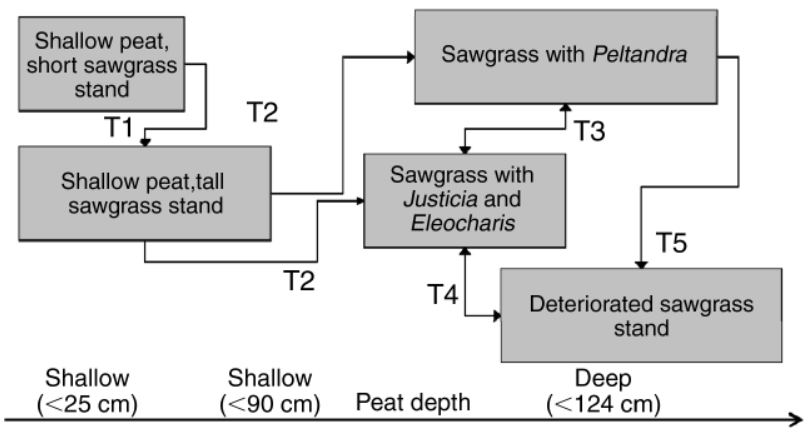

T1 = Higher water depths in the wet seasons up to 4 years previous T2 $=$ Drier mean water depths in the previous wet season

T3 $=$ Higher mean water depths in the previous wet season and higher water depths in the wet seasons up to 4 years previous

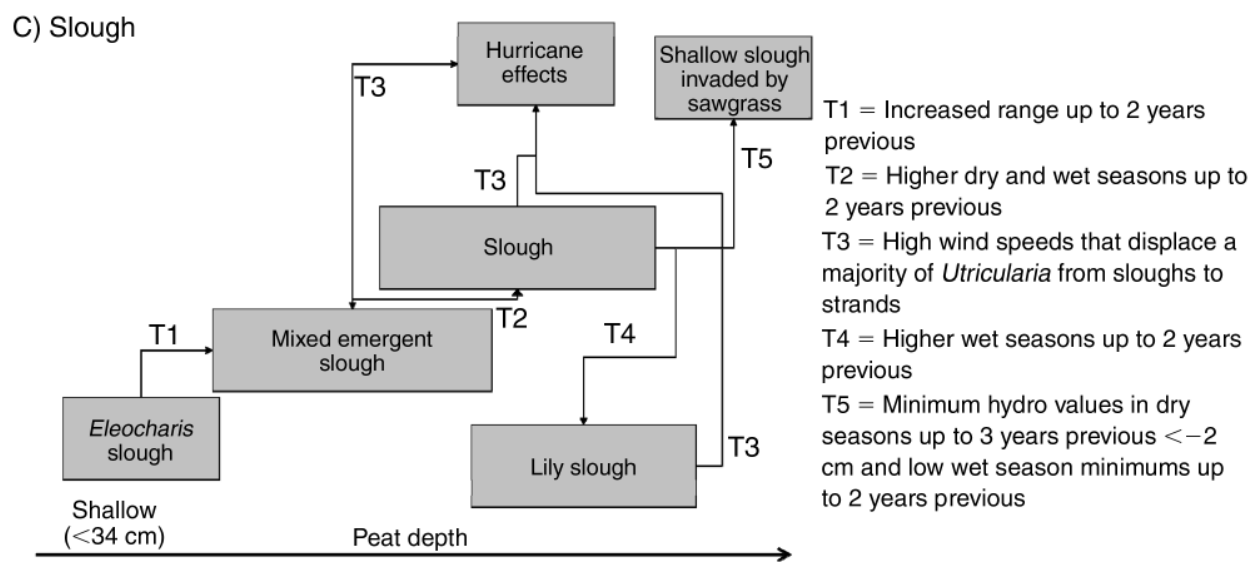

FIG. 4. State and transition model for three communities in Water Conservation Area 3A South: (A) wet prairie, (B) sawgrass, and $(\mathrm{C})$ slough. Community states are arranged on a general hydrologic gradient with drier communities at the top and deepest communities at the bottom. Two-way arrows indicate observed reversible transitions.

and slough states were affected by water depths in both the wet and dry seasons. Overall, transition occurrences were low within each community (Tables 2-4), barring the hurricane effects state, but were highest in the communities not on the extreme ends of the peat or hydrologic gradients: the less extreme states are more likely to change.

A majority of the transitions that occurred in sloughs were from the slough state to hurricane effects state in
$\mathrm{T} 1=$ Peat deposition $>25 \mathrm{~cm}$ and higher maximum values in the dry season 4 years previous, and higher mean depths in the previous dry season $\mathrm{T} 2$ = Slightly drier conditions in the dry season previous to sample and 4 years previous

T3 $=$ Maximum water depths $>79 \mathrm{~cm}$ in the wet season 1 year previous T4 = Higher water depths in the dry season previous to sample and 4 years previous

T5 = Maximum water depths $>61 \mathrm{~cm}$ in the wet season 2 years previous

$\mathrm{T} 1=$ Increased range up to 2 years

T2 = Higher dry and wet seasons up to 2 years previous

$3=$ High wind speeds that displace strands

her wet seasons up to 2 years

$\mathrm{T} 5=$ Minimum hydro values in dry

nin wet season minums up

2 years previous floating aquatic Utricularia spp. from the sloughs into the sawgrass strands. As Utricularia spp is the indicator species for the slough state, its absence is considered the hurricane effect state. Lesser effects were found in the mixed emergent and lily slough states. Transitions probabilities for any other a priori community states (sawgrass, prairie) to a hurricane effects state were small. 
TABLE 2. Transition matrix of sawgrass community states in Water Conservation Area 3A South, Florida, from 2002 to 2005.

\begin{tabular}{lcccc}
\hline \hline \multicolumn{1}{c}{ Community state } & $\begin{array}{c}\text { Sawgrass } \\
\text { with } \\
\text { Peltandra }\end{array}$ & $\begin{array}{c}\text { Shallow peat, } \\
\text { tall sawgrass } \\
\text { strand }\end{array}$ & $\begin{array}{c}\text { Shallow peat, } \\
\text { short sawgrass } \\
\text { strand }\end{array}$ & $\begin{array}{c}\text { Sawgrass with } \\
\text { Justicia } \text { and } \\
\text { Eleocharis }\end{array}$ \\
\hline Sawgrass with Peltandra & $\ldots$ & 0 & 0 & $\begin{array}{c}\text { Deteriorated } \\
\text { sawgrass } \\
\text { strand }\end{array}$ \\
Shallow peat, tall sawgrass strand & 1 & $\ldots$ & 0 & 1 \\
Shallow peat, short sawgrass strand & 0 & 0 & $\ldots$ & 0 \\
Sawgrass with Justicia and Eleocharis & 8 & 1 & 0 & 0 \\
Deteriorated sawgrass strand & 0 & 0 & 0 & 0 \\
\hline
\end{tabular}

\section{CART}

The CART analysis augmented the number of transitions in our $\mathrm{S}$ and $\mathrm{T}$ models and supplied quantitative information to annotate existing transitions. The maximum water depths of wet seasons one and two years prior to the sample were relevant to the sawgrass analysis, while the minimum of dry seasons three and four years previous to the sample were important for slough communities. The slough model classified only four of six states $(\mathrm{CV}$ error $=0.588$, misclassification rate $=0.208)$, but the sawgrass model classified all five states (CV error $=0.647$, misclassification rate $=0.238)$. CV error was high for both models.

\section{VDDT analysis}

We used the VDDT program as an exploratory application to compare different management actions for our study area using $\mathrm{S}$ and $\mathrm{T}$ models constructed from four years of data collection and to examine the results of our models over time. For the wet conditions and increased hydrologic range scenarios, there is nearly a complete disappearance of the wet prairie state and proliferation of the mixed emergent prairie, a deeper state (Fig. 5). The most dramatic changes occur in the slough and sawgrass communities. The slough state is greatly decreased, replaced by the deeper lily slough state in all but the dry conditions. The sawgrass with Justicia state decreases with the increased hydrologic range and wet-conditions scenarios and is replaced by deteriorated strand. Sawgrass with Peltandra increases in the equal and dry conditions, replacing the sawgrass with Justicia state. Increased hydrologic range is almost identical to the wet-conditions management action and, as is expected, the wet-conditions action is quite different from the dry-conditions scenario.

\section{DisCusSION}

Hydrology is the primary mechanism for multistate transitions within our study period. Water depth is a strong control of community state composition and pattern in the Everglades (Larsen et al. 2007), and we show both a recent and historic effect on vegetation, depending on community state (Fig. 4). More than two years of sustained depths over $61 \mathrm{~cm}$ in the wet season can initiate fragmentation of sawgrass communities. Drying sloughs below surface level $(-2 \mathrm{~cm})$ for three or more years coupled with low wet-season water depths allows for the encroachment of sawgrass. We do not propose that the environmental variables here are the only influences of community composition, but they are representative of the complex hydrology that affects vegetation in WCA3. The reality is that there are additional characteristics that control the composition and transition of community states, which are likely a combination of factors that incorporate duration.

The VDDT analysis is interesting in that consistent high-water conditions and increased hydrologic range (high wet season, low dry season) are very similar in their final configuration and are very different from the dry-conditions management action, particularly for the sawgrass and slough communities. The fact that drying WCA3 completely during the dry season does not seem to offset the effect of high water in the wet season could be an artifact of our data, which was collected during a four-year period of increasing wet-season maximums (C. Zweig, unpublished data). The study area experienced periods with water levels at or below ground level in the dry season, but there were no extended drought conditions. According to our model, transitioning of all three community types (slough, sawgrass, wet prairie) to deeper states occurred regardless of the management action, but the dry conditions had considerably less of

TABle 3. Transition matrix of prairie community states in Water Conservation Area 3A South, Florida, from 2002 to 2005.

\begin{tabular}{lcccc}
\hline \hline \multicolumn{1}{c}{ Community state } & $\begin{array}{c}\text { Sparse sawgrass } \\
\text { prairie }\end{array}$ & $\begin{array}{c}\text { E. elongata } \\
\text { prairie }\end{array}$ & $\begin{array}{c}\text { E. cellulosa } \\
\text { prairie }\end{array}$ & $\begin{array}{c}\text { Mixed transition } \\
\text { wet prairie }\end{array}$ \\
\hline Sparse sawgrass prairie & $\ldots$ & 0 & 0 & 0 \\
E. elongata prairie & 0 & $\ldots$ & 0 & 0 \\
E. cellulosa prairie & 1 & 0 & $\ldots$ & 0 \\
Mixed transition wet prairie & 0 & 0 & 0 & $\ldots$ \\
Wet prairie & 1 & 2 & 0 & 0 \\
\hline
\end{tabular}


TABLE 4. Transition matrix of slough community states in Water Conservation Area 3A South, Florida, from 2002 to 2005.

\begin{tabular}{|c|c|c|c|c|c|c|}
\hline Community state & $\begin{array}{l}\text { Hurricane } \\
\text { effects }\end{array}$ & $\begin{array}{l}\text { Lily } \\
\text { slough }\end{array}$ & $\begin{array}{l}\text { Eleocharis } \\
\text { slough }\end{array}$ & $\begin{array}{l}\text { Shallow slough } \\
\text { invaded by } \\
\text { sawgrass }\end{array}$ & $\begin{array}{l}\text { Mixed } \\
\text { emergent } \\
\text { slough }\end{array}$ & Slough \\
\hline Hurricane effects $\dagger$ & $\ldots$ & 0 & 0 & 0 & 0 & 0 \\
\hline Lily slough & 1 & $\cdots$ & 0 & 0 & 0 & 0 \\
\hline Eleocharis slough & 0 & 0 & $\ldots$ & 0 & 0 & 0 \\
\hline Shallow slough invaded by sawgrass & 0 & 0 & 0 & ... & 0 & 0 \\
\hline Mixed emergent slough & 1 & 0 & 0 & 0 & $\ldots$ & 1 \\
\hline Slough & 10 & 2 & $\ldots$ & 0 & 1 & $\ldots$ \\
\hline
\end{tabular}

$\dagger$ States did not transition from the hurricane effect state to another because 2005 was the last sample date.

the deeper states present (Fig. 5). Predicting 100 years into the future from four years of data strains the limits of our model, but this analysis allowed us to explore the potential use of $\mathrm{S}$ and $\mathrm{T}$ models of succession to evaluate management scenarios. Data that includes a wide range of hydrologic conditions, particularly drought, would greatly improve the current models, and improve the data-driven inputs to the models such as the CART analysis.

Although specific to the Everglades, our approach to creating $\mathrm{S}$ and $\mathrm{T}$ models is useful in other landscapes, especially those with subtle environmental gradients such as the Okavango Delta, boreal fens, and some floodplain riparian wetlands (Larsen et al. 2007) and allows scientists to address and resolve the complexity of these ecosystems. The NMS and cluster analyses can characterize states from communities that are continuous and are adaptable enough to define moving thresholds. For example, the community states in the Everglades are not characterized by the introduction or exclusion of a species as in other systems (Connell and Slayter 1977, Platt and Connell 2003, Seabloom 2007), but by the importance (biomass and density) of that species within the state (Table 1). With this method we

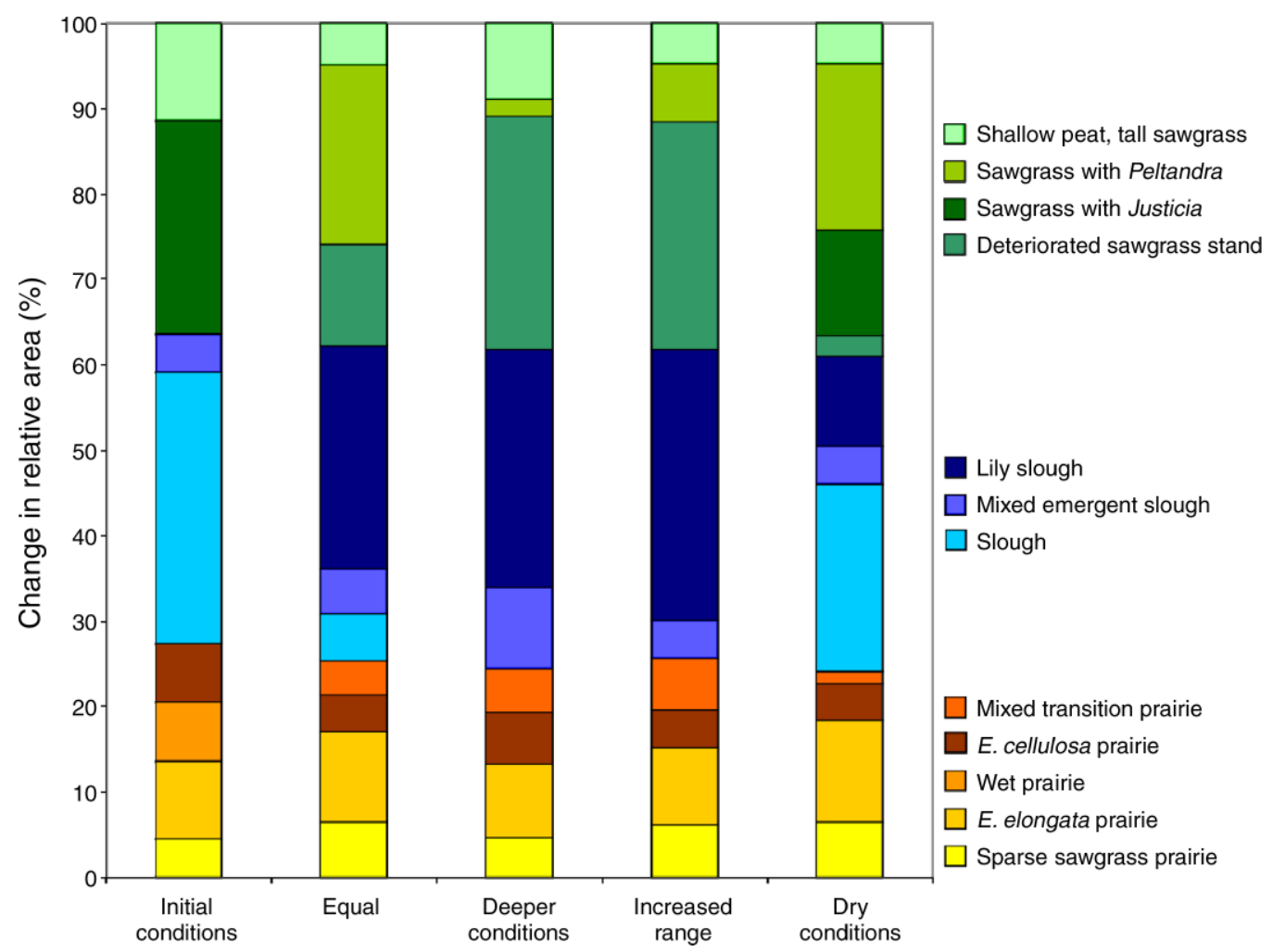

FIG. 5. Change in relative area (ha) of community states for four management scenarios in Water Conservation Area 3A South, Florida, run with Vegetation Dynamics Development Tool software. Parameters were set from data collected in 2002-2005. Initial conditions are equal to conditions in 2002. Equal = all management actions/disturbance probabilities were set equal as a control. Deeper conditions $=$ deep water depths in wet and dry season. Increased range $=$ deep water depths in wet season and very low water depths in dry season. Dry conditions = low water depths in wet and dry season. 
have defined "successional community states" which can be categorized, as with single species, with early or late successional stages. The community states are distinct in situ and not ephemeral: they are temporally persistent within our landscape but change spatially, supporting a shifting mosaic steady state model (Arscott et al. 2002). These states can be seen as variance within a larger-scale system, but that does not diminish their functional importance. While time and data-intensive, the ability to describe states at such a fine scale affords the opportunity to define a dynamic regime and create more realistic models than conventional linear relationships. As systems do not always respond in a predictable manner (Suding et al. 2004), awareness of the mechanisms of vegetation change minimizes the possibility of less desirable states (Briske et al. 2006). It also provides additional, critical information for restoration management decisions (Mayer and Rietkerk 2004) particularly as these relate to the habitat attributes for fauna.

These models provide a link between successional theory and the practice of ecosystem management. They represent the application of ecological models such as the shifting mosaic steady state model (Whited et al. 2007), alternative stable states (Beisener et al. 2003), dynamic regime (Mayer and Rietkerk 2004), and the nonequilibrium persistent model of vegetation dynamics (Suding et al. 2004). The existence of multiple stable states has been debated (Schröder et al. 2005), but we provide field evidence of multiple stable states and the ability to define states that are spatially and temporally stable within a dynamic regime. Identifying the possible states and pathways of vegetation change can be used to predict restoration success or the possibility of hysteresis: systems following a different path for recovery than the initial trajectory of change (Suding et al. 2004). We observed evidence of multiple pathways from one state to another within our study area (Fig. 4), indicating the potential for hysteresis. Managers could also explore the possibility of transitory communities that would be necessary intermediates for a final, restored system (Connell and Slayter 1977).

The concepts of multiple steady states and shifting mosaics are key theories for understanding the dynamic nature of wetlands, including the Everglades. We consider the application of these theories, our S and T succession models, as a fraction of the framework for the Everglades and our understanding will only build with time. They are hypotheses for use in adaptive management as the restoration of the Everglades continues. These models represent the community response to hydrology and illustrate which aspects of hydrologic variability are important to community structure. We intend for them to act as a foundation for further restoration management and experimentation. Future data will refine our current understanding of the impacts of altered hydrology on vegetation succession in the Everglades and increases our ability to apply succession theory to resolve restoration issues (Odum 1969).

\section{ACKNOWLEDGMENTS}

This project was funded by the U.S. Corps of Engineers. We thank the following people for their input: Peter Frederick, Rob Fletcher, Paul Wetzel, Zach Welch, Erik Powers, Andrea Bowling, and Becky Hylton.

\section{Literature Cited}

Alho, C. J. R. 2005. The Pantanal. Pages 203-271 in L. H. Fraser and P. A. Keddy, editors. The world's largest wetlands. Cambridge University Press, Cambridge, UK.

Allen-Diaz, B., and J. W. Bartolome. 1998. Sagebrush-grass vegetation dynamics: comparing classical and state-transition models. Ecological Applications 8:795-804.

Armentano, T. V., J. P. Sah, M. S. Ross, D. T. Jones, H. C. Cooley, and C. S. Smith. 2006. Rapid responses of vegetation to hydrological changes in Taylor Slough, Everglades National Park, Florida, USA. Hydrobiologia 569:293-309.

Arscott, D. B., K. Tockner, D. van der Nat, and J. V. Ward. 2002. Habitat dynamics along a braided alpine river ecosystem (Tagliamento River, northeast Italy). Ecosystems 5:802-814.

Beisner, B. E., D. T. Haydon, and K. Cuddington. 2003. Alternative stables states in ecology. Frontiers in Ecology and the Environment 1:376-382.

Bestelmeyer, B. T., J. P. Ward, and K. M. Havstad. 2006. Soilgeomorphic heterogeneity governs patchy vegetation dynamics at an arid ecotones. Ecology 87:963-973.

Beukema, S. J., W. A. Kurz, W. Klenner, J. Merzenich, and M. Arbaugh. 2003. Vegetation dynamics development tool, user's guide, Version 4.4c. ESSA Technologies Ltd., Vancouver, British Columbia, Canada.

Breiman, L., J. H. Friedman, R. A. Olshen, and C. J. Stone. 1984. Classification and regression trees. Chapman and Hall, New York, New York, USA.

Briske, D. D., S. D. Fuhlendorf, and F. E. Smeins. 2006. A unified framework for assessment and application of ecological thresholds. Rangeland Ecology and Management 59:225-236.

Connell, J. H., and R. O. Slayter. 1977. Mechanisms of succession in natural communities and their role in community stability and organization. American Naturalist 111: $1119-1144$

Conrads, P. A., E. Roehls, R. Daamen, and W. M. Kitchens. 2006. Using artificial neural network models to integrate hydrologic and ecological studies of the snail kite in the Everglades, USA. Pages 1651-1658 in P. Gourbesville, J. Cunge, V. Guinot, and S.-Y. Liong, editors. Proceedings of the 7th International Conference on Hydroinformatics. Nice, France.

Dufrêne, M., and P. Legendre. 1997. Species assemblages and indicator species: the need for a flexible asymmetrical approach. Ecological Monographs 67:345-366.

Ellery, W. N., T. S. McCarthey, and N. D. Smith. 2003. Vegetation, hydrology, and sedimentation patterns on the major distributary system of the Okavango fan, Botswana. Wetlands 23:357-375.

Givnish, T. J., J. C. Volin, V. D. Owen, V. C. Volin, J. D. Muss, and P. H. Glaser. 2008. Vegetation differentiation in the patterned landscape of the central Everglades: importance of local and landscape drivers. Global Ecology and Biogeography 17:384-402.

Junk, W. J., C. N. da Cunha, K. M. Wantzen, P. Petermann, C. Strüssmann, M. I. Marques, and J. Adis. 2006. Biodiversity and its conservation in the Pantanal of Mato Grosso, Brazil. Aquatic Science 68:278-309.

Kruskal, J. B. 1964. Nonmetric multidimensional scaling: a numerical method. Psychometrika 29:1-27. 
Kushlan, J. A. 1990. Freshwater marshes. Pages 324-363 in R. L. Myers and J. J. Ewel, editors. Ecosystems of Florida. University of Central Florida Press, Orlando, Florida, USA.

Larsen, L. G., J. W. Harvey, and J. P. Crimaldi. 2007. A delicate balance: ecohydrological feedbacks governing landscape morphology in a lotic peatland. Ecological Monographs 77:591-614.

Law, R., and R. D. Morton. 1996. Permanence and the assembly of ecological communities. Ecology 77:762-775.

Mather, P. M. 1976. Computational methods of multivariate analysis in physical geography. John Wiley and Sons, London, UK.

Mayer, A. L., and M. Rietkerk. 2004. The dynamic regime concept for ecosystem management and restoration. BioScience 54:1013-1020.

McCune, B., and M. J. Mefford. 1999. PC-ORD: multivariate analysis of ecological data v. 4.41. MjM Software Design, Medford, Oregon, USA.

Odum, E. P. 1969. The strategy of ecosystem development. Science 164:262-270.

Peet, R. K. 1992. Community structure and ecosystem function. Pages 103-151 in D. C. Glenn-Lewin, R. K. Peet, and T. T. Veblen, editors. Plant succession: theory and prediction. Chapman and Hall, London, UK.

Platt, W. J., and J. H. Connell. 2003. Natural disturbances and directional replacement of species. Ecological Monographs 73:507-522.

Proulx, R. 2007. Ecological complexity for unifying ecological theory across scales: a field ecologist's perspective. Ecological Complexity 4:85-92.

Quétier, F., A. Thébault, and S. Lavorel. 2007. Plant traits in a state and transition framework as markers of ecosystem respond to land-use change. Ecological Monographs 77:33-52.

Riscassi, A. L., and R. W. Schaffranek. 2003. Flow velocity, water temperature and conductivity in Shark River Slough, Everglades National Park, Florida. USGS open file report 03-348. U.S. Geological Survey, Reston, Virginia, USA.

Ryan, J. G., J. A. Ludwig, and C. A. Mcalpine. 2007. Complex adaptive landscapes (CAL): a conceptual framework of multi-functional, non-linear ecohydrologic feedback systems. Ecological Complexity 4:113-127.

Scheffer, M., and S. R. Carpenter. 2003. Catastrophic regime shifts in ecosystems: linking theory to observation. Trends in Ecology and Evolution 18:648-655.

Schröder, A., L. Persson, and A. M. De Roos. 2005. Direct experimental evidence for alternative stable states: a review. Oikos 110:3-19.

Seabloom, E. W. 2007. Compensation and the stability of restored grassland communities. Ecological Applications 17: $1876-1885$.

Sousa, W. P., and J. H. Connell. 1992. Grazing and succession in marine algae. Pages $425-441$ in D. M. John, S. U. Hawkins, and J. H. Price, editors. Plant-animal interactions in the marine benthos. Clarendon Press, Oxford, UK.

StatSci/Mathsoft. 1993. Statistical sciences, S-PLUS guide to statistical and mathematical analysis, Version 3.3. StatSci/ Mathsoft, Inc., Seattle, Washington, USA.

Stringham, T. K., W. C. Krueger, and P. L. Shaver. 2003. State and transition modeling: an ecological process approach. Journal of Range Management 56:106-113.

Suding, K. N., K. L. Gross, and G. R. Houseman. 2004. Alternative states and positive feedbacks in restoration ecology. Trends in Ecology and Evolution 19:46-53.

Tilman, D. 1990. Constraints and tradeoffs: towards a predictive theory of competition and succession. Oikos 58: $3-15$.

Westoby, M., B. Walker, and I. Noy-Meir. 1989. Opportunistic management for rangelands not at equilibrium. Journal of Range Management 42:266-274.

Whited, D. C., M. S. Lorang, M. J. Harner, F. R. Hauer, J. S. Kimball, and J. A. Stanford. 2007. Climate, hydrologic disturbance, and succession: drivers of floodplain pattern. Ecology 88:940-953.

Zweig, C. L., and W. M. Kitchens. 2008. Effects of landscape gradients on wetland vegetation communities: information for large-scale restoration. Wetlands 28:1086-1096. 